\title{
Hormone Replacement Therapy after Prophylactic Adnexectomy
}

\author{
Pascale This, Rémy J. Salmon, Sylvie Dolbeault, Anne de la Rochefordière, Brigitte Sigal-Zafrani, Dominique Stoppa-Lyonnet, \\ on behalf of the Institut Curie Breast and Ovarian Cancer Risk Study Group*
}

*Members of the Institut Curie Breast and Ovarian Cancer Risk Study Group: Andrieu N, Asselain B, de Cremoux P, de La Rochefordiere A, Dolbeault S, Extra JM, Fourquet A, Gauthier-Villars M, Meunier M, Salmon RJ, Sigal-Zafrani B, Stoppa-Lyonnet D, Tardivon A, Thibault F, This P

Corresponding author: Dr Pascale This, Institut Curie 26, rue d'Ulm, F-75248 Paris cedex 5, tel. 33144324647 , fax 331443245 09,e-mail: pascale.this@curie.net

Submitted: 18 September 2005

Accepted: 25 September 2005

In France, the National Collective Statement from the INSERM [1] recommends a prophylactic adnexectomy (PA) in women having an increased ovarian cancer risk due to mutations in BRCAl or BRCA2 either at 40 years of age or at 35 years of age if the woman has decided she no longer wants children. PA can reduce the risks of ovarian cancer by more than $90 \%$ and breast cancer by more than $50 \%$. However, the lack of oestrogen production caused by PA has numerous consequences. These are more pronounced in young women and include hot flushes, vaginal dryness, sexual troubles, joint stiffness and in the long term osteoporosis. Recent data from the large randomised American WHI Study [2, 3] have led the medical community to re-evaluate the benefits and risks of hormone replacement therapy (HRT) and to modify their prescription practices. As data on the HRT products used in France are not available, French agencies have recommended that in the general population HRT should be used at the lowest dose and for the shortest duration possible, and then only for menopausal problems [4]. Currently, many women in France are reluctant to use HRT because of the results of these studies. Gynaecologists also are reluctant to prescribe HRT due to the risk of legal proceedings in cases of cancer. This reluctance is much greater for women with increased risk of breast cancer. Although the Markov Model for predisposed women shows a favourable benefit/risk ratio for short-term HRT prescription, this analysis was carried out without precise data for the effect of HRT on predisposed women [5]. Moreover, breast cancer in women undergoing HRT may be falsely attributed to HRT due to the high incidence of breast cancer associated with BRCAl/2 mutations. We have observed that PA is relatively well accepted in peri-menopausal women (for example after chemotherapy), although some young women still refuse or delay PA despite there being a high incidence of ovarian cancers in their family.

At the Curie Institute, we take into account the preferences of women after they have been thoroughly informed:

1. We recommend PA to women at 40 years of age if they have a BRCA1 mutation, or a BRCA2 mutation and a family history of ovarian cancer, and at 50 years of age if they have a BRCA2 mutation without a family history of ovarian cancer.

2. In women unaffected by breast cancer, we give very complete information on the benefits and risks of HRT and alternatives, such as symptomatic treatments for hot flushes, vaginal oestrogens, and non-hormonal treatment for osteoporosis.

3. We always propose psychological support to allow each woman to estimate and anticipate the consequences of PA.

4. In case of uterine diseases such as fibroma, surgeons may propose a hysterectomy as well as $\mathrm{PA}$, in which case oestrogens can be prescribed alone and progestins can be avoided (4).

5. After PA, a gynaecological consultation is offered: HRT is given only to thoroughly informed women who really want it and have accepted PA with the assurance that they would have HRT afterwards. HRT is also offered to women who have had a prophylactic bilateral mastectomy. For other cases, 
clinical follow-up is proposed, and osteodensitometry is prescribed. If menopausal problems occur, alternative treatments are proposed first. For persistent problems, HRT is prescribed at the lowest dose for as long as the woman wishes. It is strongly recommended that treatment be stopped at the natural age of menopause, around 50 years of age.

We think that over-alarmist information on menopause and strongly held beliefs against HRT lead some young women to refuse or delay an intervention that may save their life. Therefore, we advocate clear information, honest dialogue, and shared decision making with each woman.

\section{References}

1. Eisinger F, Bressac B, Castaigne D, Cottu PH, Lansac J, Lefranc JP, Lesur A, Nogues C, Pierret J, Puy-Pernias S, Sobol H, Tardivon $\mathrm{A}$, Tristant $\mathrm{H}$ and Villet $\mathrm{R}$. Identification and management of hereditary predisposition to cancer of the breast and the ovary (update 2004). Bull Cancer 2004; 91: 219-237.

2. Rossouw JE, Anderson GL, Prentice RL, LaCroix AZ, Kooperberg C, Stefanick ML, Jackson RD, Beresford SA, Howard BV, Johnson KC, Kotchen JM and Ockene J; Writing Group for the Women's Health Initiative Investigators. Risks and benefits of estrogen plus progestin in healthy postmenopausal women: principal results From the Women's Health Initiative randomized controlled trial. JAMA 2002; 288: 321-333.

3. Anderson GL, Limacher M, Assaf AR, Bassford T, Beresford SA, Black H, Bonds D, Brunner R, Brzyski R, Caan B, Chlebowski R, Curb D, Gass M, Hays J, Heiss G, Hendrix S, Howard BV, Hsia J, Hubbell A, Jackson R, Johnson KC, Judd H, Kotchen JM, Kuller L, LaCroix AZ, Lane D, Langer RD, Lasser N, Lewis CE, Manson J, Margolis K, Ockene J, O'Sullivan MJ, Phillips L, Prentice RL, Ritenbaugh C, Robbins J, Rossouw JE, Sarto G, Stefanick ML, Van Horn L, Wactawski-Wende J, Wallace R and Wassertheil-Smoller S; Women's Health Initiative Steering Committee. Effects of conjugated equine estrogen in postmenopausal women with hysterectomy: the Women's Health Initiative randomized controlled trial. JAMA 2004; 291: 1701-1712.

4. ANAES A. Traitements hormonaux substitutifs de la ménopause, rapport d'orientation, Paris 2004. http://www.anaes.fr

5. Armstrong K, Schwartz JS, Randall T, Rubin SC and Weber B. Hormone replacement therapy and life expectancy after prophylactic oophorectomy in women with BRCA1/2 mutations: a decision analysis. J Clin Oncol 2004; 22: 1045-1054. 